\title{
CLINICAL PRESENTATION, TYPES AND TREATMENT OUTCOMES OF BILE DUCT INJURIES (BDI) IN LAPAROSCOPIC CHOLECYSTECTOMY.
}

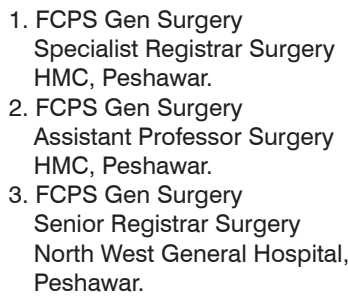

Correspondence Address:

Dr. Uzair Ahmad

H\# 36, St, Sector L-II,

Phase-III Hayatabad Peshawar.

drahmaduzair1@gmail.com

Article received on:

09/04/2019

Accepted for publication:

27/06/2019

\begin{abstract}
Uzair Ahmad', Yousaf Jan², Muhammad Uzair ${ }^{3}$
ABSTRACT... Objectives: To study the types of Biliary injuries (BDIs), their timing and clinical presentation, diagnosis and treatment outcomes in patients undergoing laparoscopic cholecystectomy. Study Design: Descriptive study. Setting: Department of General Surgery Hayatabad Medical Complex (HMC) Peshawar. Period: From October 2017 to October 2018. Materials \& Methods: including 32 patients with biliary duct injuries (BDIs). Results: This study included 32 patients with BDI, 28 patients were referred to $\mathrm{HMC}$ and 4 patients had their primary operation at Department of General Surgery HMC Peshawar. There were 23 females and 9 males with a mean age of 47 years (range, 20-65 years). After diagnostic workup, the type of BDIs was classified according to the Strasberg classification. As for BDI, 4(12.5\%) patients had a leak related to the cystic duct (Type A injury).In 11(34.3\%) patients, there was lateral injury of CBD (Type D injury). In 15(46.8\%) patients, there was complete transection of CBD (Type E injury). In $2(6.2 \%)$ patients, it was impossible to determine the cause of bile leak which was assumed to be related to aberrant ducts although this was difficult to prove. Conclusion: Laparoscopic cholecystectomy is best if done with proper training and expertise otherwise it can lead to biliary injury thus turning the patient into a "biliary cripple". They mainly result from anatomical variations and cognitive misinterpretation of anatomy .Biliary injuries can be prevented to some extent if principles of laparoscopic surgery are followed.
\end{abstract}

Key words: $\quad$ BDI (Biliary duct injuries), Cholecystectomy, Critical View, Hepatico-Jejunostomy, Peritonitis.

Article Citation: AhmadU, Jan Y,Uzair M. Clinical presentation, types and treatment outcomes of Bile Duct Injuries (BDI) in laparoscopic cholecystectomy. Professional Med J 2020; 27(2):293-299. DOI: 10.29309/TPMJ/2020.27.2.3537

\section{INTRODUCTION}

First open cholecystectomy was performed by Langenbuch in 1882 while $\mathrm{Dr}$ Erich Muhe in Germany introduced first laparoscopic cholecystectomy on Sep 12, 1985., ${ }^{1,2}$ In Sep 1992 National Institute of Health (NIH) in the US suggested that laparoscopic cholecystectomy can substitute open cholecystectomy. ${ }^{1,2}$ Over the last 3 decades laparoscopic cholecystectomy has effectively accomplished its journey from primitive method to gold standard technique and it has been rapidly accepted globally as the procedure of choice for symptomatic gall stones. ${ }^{3,4,5}$

In comparison to open cholecystectomy, laparoscopic cholecystectomy is associated with decreased post-operative pain, reduced hospital stay, early return to routine life and better cosmetic results. ${ }^{6,7}$ On the other hand laparoscopic cholecystectomy is associated with increased incidence of intraoperative injuries involving bile ducts, bowels and vascular structures..$^{3,7}$

Bile duct injury rates associated with laparoscopic cholecystectomy reached as high as $2.8 \%$ during its early phase. ${ }^{3}$ Other reports demonstrated that incidence of $\mathrm{BDI}$ has increased from $0.1 \%$ to $0.2 \%$ in the era of open cholecystectomy to $0.4 \%$ to $0.7 \%$ in the time period of laparoscopic cholecystectomy. ${ }^{5}$ In spite of all reports about $\mathrm{BDI}$ rates the actual extent of problem remains unclear, since surgeons are hesitant to disclose their own complication rates due to medico legal claims and also the complications of laparoscopic cholecystectomy are mostly managed in tertiary care centers. ${ }^{6}$

Laparoscopic complications result in part from patient selection, surgeon inexperience and technical hurdles. ${ }^{6}$ Limited view, difficult 
assessment of depth on two dimensional images, lack of tactile sensations, inappropriate skills, anatomical variations and bleeding are some of the factors resulting in $\mathrm{BDI} .^{8,9}$ Among all the factors, misidentification of anatomy appears to be the most common cause of biliary duct injuries (BDI) during laparoscopic cholecystectomy. ${ }^{6}$

BDI can be prevented by obtaining critical view of safety before clipping or dividing any tubular structure, judicious use of diathermy and safe application of clip without tenting of CBD. ${ }^{2,10}$

BDI patient are presented clinically with severe post-operative abdominal pain, fever, jaundice, and bilious discharge from drain or wound thus leading to serious consequences..$^{9,10}$

Diagnostic imaging's have important role in diagnosis of BDI.9,10 Early recognition and prompt treatment of BDI is crucial for successful outcome and it should be managed in specialized centers ${ }^{11}$ Most cases of BDI are now treated with endoscopic procedures while others still require open surgical reconstruction. ${ }^{7,8}$ The aim of this study was to determine the types of BDI, their timing and clinical presentation, diagnosis and treatment outcomes in patients undergoing laparoscopic cholecystectomy.

\section{MATERIALS AND METHODS}

This was a descriptive study carried out at Department of General Surgery Hayatabad Medical Complex Peshawar. The study was conducted from October 2017 to October 2018 including 32 patients. All cases of iatrogenic BDI after laparoscopic cholecystectomy referred to or operated at HMC during the specified period were included. Laparoscopic converted to open cholecystectomy or Open cholecystectomy BDls were excluded from the study. Patients' demographic data, mode of admission, place of previous surgery and clinical presentations at the time of admission in $\mathrm{HMC}$, timing of referral, post referral management, postreferral morbidity and mortality were analyzed in preset Performa approved by the Research Ethical Committee of the hospital. Strasberg classification was used to determine the type of injury. The diagnosis and type of IBDI was defined either by surgical recognition or imaging modalities like ultrasonography (USG), computed tomography (CT), endoscopic retrograde cholangiopancreatography (ERCP) and magnetic resonance cholangiopancreatography (MRCP). All the data was entered and analyzed by SPSS version 20 .

\section{RESULTS}

This study included 32 patients with BDI. 28 patients were referred to $\mathrm{HMC}$ and 4 patients had their primary operation at Department of General Surgery HMC Peshawar during the period from October 2017 to October 2018. There were 23 females and 9 males with a mean age of 47 years (range, 20-65years). The mostfrequent presenting signs and symptoms of BDI were Jaundice (64\%), bile leak (59\%), intra-abdominal collection (53\%), abdominal pain $(75 \%)$, peritonitis $(12 \%)$, nausea and vomiting (53\%), abdominal distention (45\%) and fever (47\%) patients. (Table-I). BDls were not recognized in any of these patients at the time of initial operation.

\begin{tabular}{|l|c|c|}
\hline \multicolumn{1}{|c|}{ Symptoms } & No. of Patients & $\%$ Age \\
\hline Jaundice & 20 & $64 \%$ \\
\hline Bile leak & 19 & $59 \%$ \\
\hline Intra-abdominal collection & 17 & $53 \%$ \\
\hline Abdominal pain & 24 & $75 \%$ \\
\hline Peritonitis & 4 & $12 \%$ \\
\hline Nausea and vomiting & 17 & $53 \%$ \\
\hline Abdominal distention & 14 & $45 \%$ \\
\hline Fever & 15 & $47 \%$ \\
\hline
\end{tabular}

Table-I. Clinical features of 32 patients with Biliary duct injuries.

Diagnostic imaging studies were conducted in all patients and included the following: USG abdomen which was done in all patients (100\%), to look for biliary channels dilatation and sub hepatic collection. Most of the USG which were done soon after operation at other hospitals had low accuracy for diagnosis of intra-abdominal collection and repeated USG done at HMC showed large intra-abdominal collection in different patients. CT scan was performed in 7 (22\%) patients to confirm bile collection and 
diffuse collection. MRCP was done in 2 patients (6\%). ERCP was performed in $23(71.8 \%)$ patients to outline biliary anatomy and judge the level of injury. ERCP stenting was done in patients presenting with leak related to the cystic duct or lateral injury of common bile duct. (Table-II).

\begin{tabular}{|l|c|c|}
\hline \multicolumn{1}{|c|}{ Imaging } & No. of Patients & \%age \\
\hline USG abdomen & 32 & $100 \%$ \\
\hline CT scan & 7 & $22 \%$ \\
\hline MRCP & 2 & $6 \%$ \\
\hline ERCP & 23 & $71.8 \%$ \\
\hline
\end{tabular}

Table-II. Diagnostic Imaging frequency in Biliary duct injuries.

After diagnostic workup, the type of BDIs was classified according to the Strasberg classification. As for BDI, 4(12.5\%) patients had a leak related to the cystic duct (Type A injury). In $11(34.3 \%)$ patients, there was lateral injury of CBD (Type D injury). In 15(46.8\%) patients, there was complete transection of CBD (Type $\mathrm{E}$ injury). In $2(6.2 \%)$ patients, it was impossible to determine the cause of bile leak which was assumed to be related to aberrant ducts although this was difficult to prove.

Only (28.1\%) 9 patients were managed without surgical intervention (including those patients who were treated with ERCP stenting and US-guided drainage). Conservative treatment was given to only 2 patients who presented with bilious discharge in sub hepatic drain. They were not toxic. They were under observation. The leak stopped within 7 days without any intervention. Of the 4 patients with cystic duct problems (Type A injury), 2 could be treated with ERCP stenting and Ultrasound guided percutaneous drainage, whereas 2 patients had to undergo an open procedure with closure of the cystic duct stump. In case of Type $D$ injury 5 patients were treated with ERCP stenting and Ultrasound guided percutaneous drainage, 4 patients underwent open exploration with repair of CBD over $\mathrm{T}$ tube and in 2 patient's repair of CBD injury was not possible so biliary enteric anastomosis was preformed. In case of Type E injury 14 patient undergone hepatico-jejunostomy and in 1 patient due to dense adhesions and difficult anatomy further intervention was not possible. Only peritoneal lavage was done, sub hepatic and pelvic drains were placed and patient was referred to specialized hepato-biliary center. 23 (71.8\%) patients underwent operative surgery in the form of hepatico-jejunostomy, drainage with a T-tube insertion in the CBD and closure of the cystic duct stump. Among those patients who were managed surgically the most common operation was hepatico-jejunostomy (50\%) 16 patients.

Overall mortality was $6.2 \%$ (2 patients). One patient died from septicemia with multi-organ failure secondary to biliary peritonitis. Another patient died from pulmonary embolism.

Patients presented in time interval between previous surgery and onset of symptoms after getting biliary injury complication was $30(93.7 \%)$ within one month and only $2(6.2 \%)$ patients within 6 months. The mean hospital stay was $15 \pm 7$ days (range 7-30 days). Injuries and their treatment are summarized in [Table-III] and [Table-IV].

\begin{tabular}{|l|c|c|}
\hline \multicolumn{1}{|c|}{ Type } & No. of Patients & $\%$ Age \\
\hline $\begin{array}{l}\text { A: Cystic or aberrant } \\
\text { ducts leak }\end{array}$ & 4 & $12.5 \%$ \\
\hline $\begin{array}{l}\text { D: Lateral injuries to } \\
\text { major bile ducts }\end{array}$ & 11 & $34.3 \%$ \\
\hline $\begin{array}{l}\text { E: Complete transection } \\
\text { of major bile ducts }\end{array}$ & 15 & $46.8 \%$ \\
\hline $\begin{array}{l}\text { Undetermined } \\
\text { Table-III. Distribution of bile duct injuries in 32 } \\
\text { patients according to Strasberg classification. }\end{array}$ \\
\hline
\end{tabular}

\begin{tabular}{|l|c|c|}
\hline \multicolumn{1}{|c|}{ Treatment } & Frequency & $\%$ Age \\
\hline Conservative & 2 & $6.2 \%$ \\
\hline ERCP + USG guided drainage & 7 & $21.8 \%$ \\
\hline $\begin{array}{l}\text { End-to-end anastomosis over } \\
\text { a T-tube }\end{array}$ & 4 & $12.5 \%$ \\
\hline Cystic duct ligation & 2 & $6.2 \%$ \\
\hline Biliary Enteric Anastomosis & 16 & $50 \%$ \\
\hline Peritoneal lavage + Referral & 1 & $3.1 \%$ \\
\hline $\begin{array}{l}\text { Total } \\
\text { Table-IV. Treatment of 32 patients with Biliary duct } \\
\text { injuries. }\end{array}$ & 32 & $100 \%$ \\
\hline
\end{tabular}




\section{DISCUSSION}

Bile duct injury is one of the major complications of laparoscopic cholecystectomy. Anatomical variations, local pathology and lack of professional skills are the main factors responsible for BDI. ${ }^{12}$ $\mathrm{BDI}$ in one large study the main cause of error in $97 \%$ of patients was cognitive misperception of anatomy. Faults in technical expertise of the surgeon were present in only $3 \%$ of cases. ${ }^{13}$ Only $25 \%-32.4 \%$ of injuries are noticed during the operation, which is regarded as the appropriate time to repair. ${ }^{14}$ The cognitive misinterpretation of anatomy is so compelling that injuries are rarely noticed at the time of operation and surgery may thought to be normal. ${ }^{15}$ In our study BDls were not recognized in any of these patients at the time of initial operation.

The most frequent presenting signs and symptoms of BDI were Jaundice (64\%), bile leak (59\%), intra-abdominal collection (53\%), abdominal pain $(75 \%)$, peritonitis $(12 \%)$, nausea and vomiting (53\%), abdominal distention (45\%) and fever (47\%) patients which are mostly in accordance with the study of Aziz AM et all. ${ }^{8}$

Diagnostic imagings have important role in diagnosis and management of BDI. Ultrasonography is the first diagnostic tool in BDI which was done in all patients (100\%), Most of the USG which were done soon after operation at other hospitals had low accuracy for diagnosis of intraabdominal collection and repeated USG done at $\mathrm{HMC}$ showed large intra-abdominal collection in different patients, an observation in agreement with Bra ghetto et al. ${ }^{16} \mathrm{ERCP}$ stenting was done in patients with leak related to cystic duct or partial thickness injury of common bile duct (CBD). ERCP gives the most definitive information on the status of the biliary system. It has also therapeutic role in the form of sphincterotomy, clearance of stones, and stenting to prevent building up of pressure in biliary tree thus causing the leak to heal. ${ }^{17}$

The management of BDIs can be divided into non operative and operative treatment. The technique and timing of repair depends on numerous factors such as: severity of injury, technical skills of the surgeon, extent of acute inflammation and hemodynamic status of the patient. ${ }^{18}$ According to the literature, there may be a minor leak, arising from a small, accessory duct and clinically insignificant. Such cases should be managed conservatively. ${ }^{19}$ The indications for conservative treatment are biliary leak less than $300 \mathrm{ml}$ and no signs of peritonitis. Ultrasonography should be done to exclude sub hepatic collection. Maintaining uninterrupted biliary drainage and taking care of intra-abdominal drain to avoid its slippage is crucial. After several weeks bile leak would subside. ${ }^{20}$

In case of type $D$ injury, primary repair of CBD on T-tube is recommended. In case of complete transection of $C B D$ or aberrant duct $(B, C$ and $E$ types) and great substance loss, immediate bilioenteric anastomosis in the form of Roux-Y hepaticojejunostomy is the preferred method. ${ }^{21}$ In case of complete transection of CBD with no substance loss direct anastomosis between the cut ends on a drain can be performed. ${ }^{22}$ If the surgeon is not clear about the type of biliary injury, damage control surgery in the form of drainage of the hepatic pedicle and sub-hepatic area should be performed, and patient should be transferred to a specialized hepato- biliary center. ${ }^{23}$ This was also the main policy at our department.

Only $(28.1 \%) 9$ patients were managed without surgical intervention (including those patients who were treated with ERCP stenting and US-guided drainage). Conservative treatment was given to only 2 patients who presented with bilious discharge in sub hepatic drain. They were under observation. The leak stopped within 7 days. Of the 4 patients with Type A injury, 2 could be treated with ERCP stenting and Ultrasound guided percutaneous drainage, whereas 2 patients had to undergo an open procedure with closure of the cystic duct stump. In case of Type D injury 5 patients were treated with ERCP stenting and Ultrasound guided percutaneous drainage, 4 patients underwent open exploration with repair of CBD over T tube and in 2 patient's repair of CBD injury was not possible so biliary enteric anastomosis was preformed. In case of Type $\mathrm{E}$ injury 14 patient undergone hepatico-jejunostomy 
and in 1 patient due to dense adhesions and difficult anatomy further intervention was not possible. Only peritoneal lavage was done, sub hepatic and pelvic drains were placed and patient was referred to specialized Hepatobiliary center. $23(71.8 \%)$ patients underwent operative surgery in the form of hepatico-jejunostomy, drainage with a T-tube insertion in the CBD and closure of the cystic duct stump. Among those patients who were managed surgically the most common operation was hepatico-jejunostomy (50\%) 16 patients.

It is found that in comparison to straightforward cholecystectomy long-term quality of life is reduced in patients with bile duct injuries. ${ }^{24}$ Overall mortality was $6.2 \%$ (2 patients). One patient was $52 y$ rs old diabetic women. She had type E injury for which laparotomy with biliary enteric anastomosis was performed. She died from septicemia with multi-organ failure secondary to biliary peritonitis on $7^{\text {th }}$ post-operative day. Another patient was $60 y r s$ old man. He had type D injury for which laparotomy with repair of CBD over $T$ tube was performed. He died from pulmonary embolism on $4^{\text {th }}$ post-operative day. In a review of 15 studies, it was noticed that postoperative mortality was $2.7 \%{ }^{25}$ In a study published in 1982 , the mortality reported was much high (i.e., 8.6\%). ${ }^{26}$ In another study conducted by Mannan A et all ${ }^{10}$ mortality was $25 \%$ which was due to peritonitis and multiorgan failure.

It is found that biliary injuries occurring during laparoscopic cholecystectomy are usually more severe than those occurring during open cholecystectomy, thus BDI should always be prevented. ${ }^{27}$ Bile duct injury should be regarded as preventable, but over 70 per cent of surgeons consider it as unavoidable. ${ }^{28}$ Several techniques were proposed to prevent Biliary injuries such as: judicious use of cautery, obtaining critical view of safety, avoidance of excessive dissection near cystic duct common hepatic duct junction, and conversion to open cholecystectomy when in doubt. $^{29}$

Study biased by follow up for long term complications such biliary strictures, cholangitis, hepatic failure etc. Such data is important, and future studies should include such data. In our hospital, most of the patients came from far flung areas. Hence, long term complications data could not be recorded.

\section{CONCLUSION}

Laparoscopic cholecystectomy is best if done with proper training and expertise otherwise it can lead to biliary injury thus turning the patient into a "biliary cripple". They mainly result from anatomical variations and cognitive misinterpretation of anatomy. Biliary injuries can be prevented to some extent if principles of laparoscopic surgery are followed. Multidisciplinary management in tertiary centers should be recommended. Patients in whom injuries are recognized on table and managed in same setting have the best results but it is a technically demanding. Patients presented late have more chances of morbidity and mortality.

Copyright (C) 27 June, 2019.

\section{REFERENCES}

1. Martin D, Uldry E, Demartines N, Halkic N. Bile duct injuries after laparoscopic cholecystectomy: 11-year experience in a tertiary center. Bioscience trends. 2016; 10(3):197-201.

2. El-Sadig M. Laparoscopic cholecystectomy complications in a tertiary hospital (Oman). Sudan Med J. 2017 Dec; 53(3):119-24.

3. Hogan NM, Dorcaratto D, Hogan AM, Nasirawan F, Mc Entee P, Maguire D, Geoghegan J, Traynor O, Winter DC, Hoti E. latrogenic common bile duct injuries: Increasing complexity in the laparoscopic era: $A$ prospective cohort study. International Journal of Surgery. 2016 Sep 1; 33:151-6.

4. Sabah A, Alkumasi HA, AIGhadhban MR. Incidence of major biliary injuries associated with laparoscopic cholecystectomy at Al-Karama teaching hospital, Baghdad, Iraq. International Surgery Journal. 2018 Feb 26; 5(3):827-33.

5. Gao Z, Li P, Chen F, Tan D. The clinical analysis of bile duct injury during laparoscopic cholecystectomy. International Journal of Clinical Medicine. 2015 Nov 10; 6(11):825. 
6. Chaudhari DR, Patel JC, Parikh JV. Comparison of common bile duct injury, biliary peritonitis, jaundice and wound infection as complication in cases of open and laparoscopic cholecystectomies. Int J Res Med. 2017; 6(2):24-8.

7. Viste A, Horn A, Øvrebø K, Christensen B, Angelsen JH, Hoem D. Bile duct injuries following laparoscopic cholecystectomy. Scandinavian Journal of Surgery. 2015 Dec; 104(4):233-7.

8. Aziz AM, Shoreem H, Sallam A, Al-Warraky M, Sadek A, Osman $M$. latrogenic bile duct injury: $A$ retrospective analysis of short-and long-term outcomes after surgical repair. Saudi Surgical Journal. 2016 May 1; 4(2):61.

9. Bader HA. latrogenic biliary injuries in patients who underwent laparoscopic cholecystectomy. The Scientific Journal of Al-Azhar Medical Faculty, Girls. 2018 Jan $1 ; 2(1): 11$

10. Mannan A, Soomro SA, Bhanbhro RJ, Ghauri A, Laghari $\mathrm{MH}$. Common bile duct injury; management and outcome study at Isra University Hospital Hyderabad Sindh. Professional Medical Journal. 2015 Oct 1; 22(6).

11. Gohel JB, Sharma D, Patel NB, Raswan US, Patil S. A study of incidence and different treatment modalities for bile duct injury and bile leakage in 200 cases of laparoscopic cholecystectomy. International Journal of Medical Science and Public Health. 2016 Apr 1; 5(4):754-8.

12. Al-Kubati WR. Bile duct injuries following laparoscopic cholecystectomy: A clinical study. Saudi journal of gastroenterology: official journal of the Saudi Gastroenterology Association. 2010 Apr; 16(2):100.

13. Jabłońska B, Lampe P, Olakowski M, Górka Z, Lekstan A, Gruszka T. Hepaticojejunostomy vs. end-to-end biliary reconstructions in the treatment of iatrogenic bile duct injuries. Journal of gastrointestinal surgery. 2009 Jun $1 ; 13(6): 1084-93$.

14. Soper NJ. Prevention of biliary leaks. Journal of Gastrointestinal Surgery. 2011 Jun 1; 15(6):1005.

15. Bharathy KG, Negi SS. Post cholecystectomy bile duct injury and its sequelae: Pathogenesis, classification, and management. Indian Journal of Gastroenterology. 2014 May 1; 33(3):201-15.

16. Braghetto I, Bastias $J$, Csendes A, Debandi A. Intraperitoneal bile collections after laparoscopic cholecystectomy. Surgical endoscopy. 2000 Nov 1; 14(11):1037-41.

17. Rustagi T, Aslanian HR. Endoscopic management of biliary leaks after laparoscopic cholecystectomy.
Journal of clinical gastroenterology. 2014 Sep 1; 48(8):674-8.

18. Karvonen J, Grönroos JM, Mäkitalo L, Koivisto M, Salminen P. Quality of life after iatrogenic bile duct injury-a case control study. Minimally Invasive Therapy \& Allied Technologies. 2013 Jun 1; 22(3):17780.

19. Balija M, Huis M, Szerda F, Bubnjar J, Stulhofer M. Laparoscopic cholecystectomy--accessory bile ducts. Acta medica Croatica: casopis Hravatske akademije medicinskih znanosti. 2003; 57(2):105-9.

20. Lovecek M, Havlik R, Klein J, Malý T, Köcher M, Cerna $M$, Král V, Neoral C. Iatrogenic bile ducts injuries. Rozhledy v chirurgii: mesicnik Ceskoslovenske chirurgicke spolecnosti. 2010 Mar; 89(3):183-7.

21. Pekolj J, Alvarez FA, Palavecino M, Clariá RS, Mazza $O$, de Santibañes E. Intraoperative management and repair of bile duct injuries sustained during 10,123 laparoscopic cholecystectomies in a high-volume referral center. Journal of the American College of Surgeons. 2013 May 1; 216(5):894-901.

22. De Reuver PR, Busch OR, Rauws EA, Lameris JS, Van Gulik TM, Gouma DJ. Long-term results of a primary end-to-end anastomosis in preoperative detected bile duct injury. Journal of Gastrointestinal Surgery. 2007 Mar 1; $11(3): 296-302$.

23. Stewart L, Way LW. Laparoscopic bile duct injuries: Timing of surgical repair does not influence success rate. A multivariate analysis of factors influencing surgical outcomes. HPB. 2009 Sep 1; 11(6):516-22.

24. Landman MP, Feurer ID, Moore DE, Zaydfudim V, Pinson $\mathrm{CW}$. The long-term effect of bile duct injuries on health-related quality of life: A meta $\square$ analysis. Hpb. 2013 Apr; 15(4):252-9.

25. Sicklick JK, Camp MS, Lillemoe KD, Melton GB, Yeo CJ, Campbell KA, Talamini MA, Pitt HA, Coleman J, Sauter PA, Cameron JL. Surgical management of bile duct injuries sustained during laparoscopic cholecystectomy: Perioperative results in 200 patients. Annals of Surgery. 2005 May; 241(5):786.

26. Warren $\mathrm{KW}$. The evaluation and current perspectives of the treatment of benign bile duct strictures. A review Surg Gastroenterol. 1982; 1:141-54.

27. Francoeur JR, Wiseman K, Buczkowski AK, Chung SW, Scudamore CH. Surgeons' anonymous response after bile duct injury during cholecystectomy. The American journal of surgery. 2003 May 1; 185(5):468-75. 
28. Hugh TB. New strategies to prevent laparoscopic bile duct injury-surgeons can learn from pilots. Surgery. 2002 Nov 1; 132(5):826-35.
29. Slater K, Strong RW, Wall DR, Lynch SV. latrogenic bile duct injury: The scourge of laparoscopic cholecystectomy. ANZ journal of surgery. 2002 Feb; 72(2):83-8.

\section{AUTHORSHIP AND CONTRIBUTION DECLARATION}

\begin{tabular}{|c|l|l|}
\hline Sr. \# & Author(s) Full Name & \multicolumn{1}{|c|}{ Contribution to the paper } \\
\hline 1 & Uzair Ahmad & $\begin{array}{l}\text { Principal author, Data collection, } \\
\text { Writing of manuscript. } \\
\text { Data collection, Analysis, Critical } \\
\text { review of manuscript, compilation. } \\
\text { Literature and References } \\
\text { collection, Final Proof reading. }\end{array}$ \\
\hline 3 & Yousaf Jan & Muhammad Uzair
\end{tabular}

